\title{
ANALISIS PRODUKTIVITAS DAN KEUNTUNGAN USAHATANI BUAH NAGA BERDASARKAN SKALA USAHA DI KECAMATAN TEGALSARI, KABUPATEN BANYUWANGI
}

\section{ANALYSIS OF PRODUCTIVITY AND BENEFITS OF THE DRAGON FRUIT FRAM BASED ON BUSINESS SCALE IN TEGALSARI DISTRICT, REGENCY OF BANYUWANGI}

\author{
Nana Lutfi Sintia ${ }^{1}$, Henik Prayuginingsih ${ }^{2}$, Fefi Nurdiana Wijayanti ${ }^{2}$
}

1) Mahasiswa Program Studi Agribisnis, Fakultas Pertanian, Universitas Muhammadiyah Jember

2) Dosen Program Studi Agribisnis, Fakultas Pertanian, Universitas Muhammadiyah Jember e-mail: nana.lutfi03@gmail.com

\begin{abstract}
ABSTRAK
Tujuan penelitian ini adalah; (1) Untuk mengetahui produktivitas usahatani buah naga skala sempit lebih rendah dan skala luas; (2) Untuk mengetahui biaya produksi usahatani buah naga skala sempit dan skala luas; (3) Untuk mengetahui keuntungan usahatani buah naga skala sempit dan skala luas. Jenis penelitian ini adalah metode deskriptif dan survey dengan lokasi penelitian dipilih secara purposive method, yaitu di Kecamatan Tegalsari, Kabupaten Banyuwangi. Pengambilan sampel dilakukan menggunakan metode Disproportioned Random Sampling. Data yang digunakan adalah data primer dan data sekunder. Teknik pengumpulan data dilakukan dengan teknik wawancara dan instansi. Analisis data menggunakan uji beda Z. Berdasarkan hasil penelitian, dapat disimpulkan bahwa; (1) Produktivitas usahatani buah naga untuk petani skala sempit lebih rendah dibandingkan dengan skala luas. Produktivitas buah naga untuk golongan petani skala sempit sebesar $7.190 \mathrm{~kg} / \mathrm{ha}$, sedangkan untuk skala luas sebesar $8.883 \mathrm{~kg} / \mathrm{ha}$. Perbedaan ini secara statistik signifikan pada taraf uji 1\%; (2) Biaya produksi usahatani buah naga untuk petani skala sempit lebih besar dibandingkan dengan skala luas. Biaya produksi untuk golongan petani skala sempit sebesar Rp. 24.982.190/ha dan skala luas sebesar Rp. 21.022.842/ha. Perbedaan ini secara signifikan pada taraf uji 5\%; (3) Keuntungan usahatani buah naga untuk petani skala sempit lebih rendah dibandingkan dengan skala luas. Keuntungan usahatani buah naga golongan petani sempit sebesar Rp. 32.539.379/ha dan skala luas sebesar Rp. 50.043.825/ha. Perbedaan ini secara signifikan pada taraf uji 5\%.
\end{abstract}

Kata Kunci: Biaya, Produktivitas, Keuntungan, Buah Naga.

\section{ABSTRACT}

The purpose of this research is; (1) To know the productivity of dragon fruit farms on a narrow scale lower and wider scale; (2) To know the cost of production of dragon fruit farms on a narrow scale and wide scale; (3) To know the advantages of dragon fruit farms on a narrow scale and large scale. The type of this research is descriptive method and survey with research location chosen by purposive method, that is in District Tegalsari, Regency of Banyuwangi. Sampling was conducted using the method of Disproportioned Random Sampling. The data used are primary data and secondary data. Technique of data collecting is done by interview and institution technique. Data analysis using different test $Z$. Based on the research, it can be concluded that; (1) Productivity of dragon fruit farming for small scale farmers is lower than that of large scale. Dragon fruit productivity for the farmers of the narrow scale of $7190 \mathrm{~kg} / \mathrm{ha}$, while for the scale of $8,883 \mathrm{~kg} / \mathrm{ha}$. This difference is statistically significant at the $1 \%$ test level; (2) The production cost of dragon fruit farming for small scale farmers is bigger than large scale. Production cost for a small scale farmers group of Rp. 24,982,190 / ha and the scale of Rp. 21,022,842 / ha. This difference is significant at the 5\% test level; (3) The profit of dragon fruit farming for small scale farmers is lower than that of large scale. Profits of dragon fruit farming farmers group of Rp. 32,539,379/ ha and the scale of Rp. 50,043,825 / ha. This difference is significant at the 5\% test level. Keywords: Cost, Productivity, Profit, Dragon Fruit 


\section{PENDAHULUAN}

Menurut Adiyanto (2011), keadaan alam dan iklim Indonesia memungkinkan dilakukannya budidaya tanaman hortikultura baik varietas lokal maupun internasional. Salah satu komoditas tanaman hortikultura yaitu dari jenis buah-buahan yang sekarang ini marak dikembangkan dan dibudidayakan yaitu tanaman buah naga. Perkembangan luas lahan, produksi dan produktivitas buah naga di Kabupaten Banyuwangi tahun 2012-2015 disajikan pada Tabel 1.

Tabel 1. Perkembangan Luas Lahan, Produksi dan Produktivitas Buah Naga di Kabupaten Banyuwangi Tahun 2012-2015

\begin{tabular}{ccccccc}
\hline Tahun & $\begin{array}{c}\text { Luas Lahan } \\
(\mathbf{h a})\end{array}$ & Perkembangan $(\boldsymbol{\%})$ & $\begin{array}{c}\text { Produksi } \\
(\mathbf{k w})\end{array}$ & $\begin{array}{c}\text { Perkembangan } \\
(\boldsymbol{\%})\end{array}$ & $\begin{array}{c}\text { Produktivitas } \\
(\mathbf{k w} / \mathbf{h a})\end{array}$ & $\begin{array}{c}\text { Perkembanga } \\
\mathbf{n}(\boldsymbol{\%})\end{array}$ \\
\hline 2012 & 539 & - & $12.936,00$ & - & 240 \\
2013 & 678,80 & 25,94 & $16.630,60$ & 28,56 & 245 & 2,08 \\
2014 & $1.152,80$ & 69,83 & $28.820,00$ & 73,30 & 2,04 & 250 \\
2015 & $1.213,33$ & 5,25 & $30.454,08$ & 5,67 & 251 & 246,5 \\
\hline $\begin{array}{c}\text { Rata- } \\
\text { rata }\end{array}$ & 895,98 & 33,67 & $22.210,17$ & 35,84 & 1,51 \\
\hline
\end{tabular}

Sumber: Badan Pusat Statistik Kabupaten Banyuwangi 2016.

Hingga saat ini kebutuhan akan buah naga di Indonesia cukup besar. Kebutuhan tersebut belum mampu dipenuhi, baik oleh produsen di dalam negeri maupun di luar negeri, sehingga peluang untuk membudidayakan buah naga masih sangat terbuka, baik untuk pasaran lokal maupun internasional. Peluang usaha buah naga sangat menjanjikan, tidak saja untuk konsumsi segar tetapi juga untuk produk kesehatan (Departemen Pertanian, 2015). Dalam permasalahan kebutuhan buah naga yang masih belum terpenuhi oleh produsen di dalam negeri, maka upaya yang dilakukan untuk meningkatkan kebutuhan buah naga dalam negeri yaitu dengan cara meningkatkan hasil produksi buah naga dalam negeri oleh petani buah naga. Setelah meningkatkan produksi maka diharapkan produktivitas buah naga juga ikut meningkat. Luas lahan garapan buah naga semakin luas. Oleh karena itu tujuan penelitian ini meliputi: 1) Untuk mengetahui produktivitas usahatani buah naga skala sempit dan skala luas, 2) Untuk mengetahui biaya produksi usahatani buah naga skala sempit dan skala luas, dan 3) Untuk mengetahui keuntungan usahatani buah naga skala sempit dan skala luas.

\section{METODOLOGI PENELITIAN}

\section{Metodologi Penelitian}

Metode yang digunakan dalam penelitian adalah metode deskriptif dan survey. Menurut (Singarimbun, 1981) penelitian deskriftif bertujuan untuk menggambarkan peristiwa (fenomena) secara sistematis, aktual dan akurat mengenai faktafakta dan sifat populasi atau daerah tertentu. Metode survey merupakan cara untuk mengumpulkan data dari sejumlah unit atau individu dalam jangka waktu tertentu secara bersamaan, metode survey serta melakukan wawancara secara langsung kepada petani atau responden (Singarimbun, 1981). Penelitian ini juga menggunakan metode komparatif. Metode komparatif digunakan karena penelitian ini membandingkan besarnya produktivitas, besarnya biaya produksi serta besarnya keuntungan usahatani buah naga berdasarkan skala usaha.

\section{Penentuan Lokasi Penelitian}

Daerah penelitian ditentukan secara purposive (sengaja), dan lokasi penelitian dilaksanakan di Kecamatan Tegalsari Kabupaten Banyuwangi. Penentuan lokasi penelitian dilakukan secara purposive atau sengaja dengan pertimbangan bahwa komoditas buah naga di Kecamatan Tegalsari Kabupaten Banyuwangi relatif baru sehingga perlu diketahui apakah usahatani buah naga memberikan keuntungan.

\section{Metode Pengambilan Sampel}

Metode pengambilan sample yang digunakan adalah Disproportioned Random Sampling, yaitu teknik yang digunakan untuk menentukan jumlah sample bila populasi berstrata tapi kurang proporsional. Hal ini karena di lokasi penelitian populasi petani buah naga antar skala sempit dan skala luas 
kurang berimbang. Populasi petani buah naga skala sempit sebesar 52 orang, sedangkan jumlah petani buah naga skala luas sebesar 11 orang. Dengan jumlah sampel terdiri 44, 10 samlpe petani skala luas dan 34 sampe petani skala sempit.

\section{Metode Pengumpulan Data}

Dalam penelitian ini jenis data yang digunakan terdiri dari dua macam yaitu data primer dan data sekunder. Data primer dikumpulkan melalui teknik wawancara. Data sekunder dikumpulkan dari instansi yang terkait dengan penelitian.

\section{Metode Analisis Data}

Metode analisis data yang digunakan untuk menguji hipotesis dalam penelitian adalah:

1. Untuk mengukur besarnya produktivitas usahatani buah naga digunakan pendekatan Average Physical Product (APP) dengan formulasi sebagai berikut (Boediono, 1982) :

$$
A P P=\frac{T P P}{X}=\frac{Q}{X}=\frac{f(X)}{X}
$$

di mana:

$\mathrm{APP}=$ produksi rata-rata per satuan input $\mathrm{TPP}=$ produksi total

$\mathrm{Q}=$ output atau produksi yang dihasilkan $\mathrm{X}=$ luas lahan

Sedangkan untuk mengetahui dugaan produktivitas usahatani buah naga skala sempit lebih rendah dibandingkan dengan skala luas digunakan uji-Z.

$\mathrm{H}_{0}$ : Produktivitas usahatani buah naga skala sempit lebih tinggi dibandingkan dengan skala luas, atau $\mu_{1} \geq \mu_{2}$

$\mathrm{H}_{\mathrm{a}}$ : Produktivitas usahatani buah naga skala sempit lebih rendah dibandingkan dengan skala luas, atau $\mu_{1}<\mu_{2}$

Kriteria pengambilan keputusan adalah:

a. Jika $\mathrm{Z}_{\text {hitung }} \leq \mathrm{Z}_{(\alpha / 2)}$, maka $\mathrm{H}_{0}$ diterima dan $\mathrm{H}_{\mathrm{a}}$ ditolak

b. Jika $\mathrm{Z}_{\text {hitung }}>\mathrm{Z}_{(\alpha / 2)}$, maka $\mathrm{H}_{0}$ ditolak dan $\mathrm{H}_{\mathrm{a}}$ diterima

Jika $\mathrm{Z}$ hitung $\leq \mathrm{Z}$ tabel, maka dapat dinyatakan bahwa perbedaan produktivitas usahatani buah naga berdasarkan skala usaha secara statistik tidak signifikan. Akan tetapi, apabila terbukti bahwa $\mathrm{Z}$ hitung $>\mathrm{Z}$ tabel, maka dari itu uji-Z tersebut dihasilkan kesimpulan yang memutuskan bahwa $\mathrm{H}_{0}$ ditolak dan $\mathrm{H}_{\mathrm{a}}$ diterima. Pengujian sampel menggunakan uji $\mathrm{Z}$ dengan rumus sebagai berikut (Supranto, 2009):

$$
z=\frac{\left(\bar{X}_{1}-\bar{X}_{2}\right)-\left(\mu_{1}-\mu_{2}\right)}{\sqrt{\frac{\sigma_{1}^{2}}{n_{1}}+\frac{\sigma_{2}^{2}}{n_{2}}}}
$$

di mana:

$\bar{X}_{1}$ dan $\bar{X}_{2}=$ nilai rata-rata dari sampel -1 dan -2 yang diamati

$\left(\mu_{1}-\mu_{2}\right)=$ perbedaan antara rata-rata populasi yang dihipotesiskan

$\sigma_{1}^{2}$ dan $\sigma_{2}^{2}=$ varians dari populasi -1 dan populasi- 2

$n_{1}$ dan $n_{2}=$ ukuran dari sampel -1 dan sampel -2

di mana apabila $\sigma_{1}^{2}$ dan $\sigma_{2}^{2}$ tak diketahui, dapat diestimasi dengan:

$$
z=\frac{\left(\bar{X}_{1}-\bar{X}_{2}\right)-\left(\mu_{1}-\mu_{2}\right)}{\sqrt{\frac{s_{1}^{2}}{n_{1}}+\frac{s_{2}^{2}}{n_{2}}}}
$$

di mana:

$\bar{X}_{1}$ dan $\bar{X}_{2}=$ nilai rata - rata dari sampel -1 dan sampel -2 yang diamati $\left(\mu_{1}-\mu_{2}\right)=$ perbedaan antara rata-rata populasi yang dihipotesiskan

$s_{1}^{2}$ dan $s_{2}^{2}=$ varians dari populasi - 1 dan populasi - 2 $n_{1}$ dan $n_{2}=$ ukuran dari sampel - 1 dan sampel - 2

2. Pengujian hipotesis yang kedua mengenai dugaan biaya produksi usahatani buah naga skala sempit lebih tinggi dibandingkan skala luas. Untuk mengukur biaya produksi usahatani buah naga digunakan pendekatan teori biaya dengan formulasi sebagai berikut (Soekartawi, 1995):

$$
\mathrm{TC}=\mathrm{TFC}+\mathrm{TVC}
$$

di mana :

$\mathrm{TC}=($ Total Cost $)$ Total Biaya

$\mathrm{TFC}=($ Total Fixed Cost $)$ Total Biaya Tetap

$\mathrm{TVC}=($ Total Variable Cost $)$ Total Biaya Variabel

Sedangkan untuk mengetahui dugaan biaya produksi usahatani buah naga skala sempit lebih tinggi dibandingkan skala luas digunakan uji-Z. 
$\mathrm{H}_{0}$ : Biaya produksi usahatani buah naga skala sempit lebih rendah dibandingkan dengan skala luas, atau $\mu_{1} \leq \mu_{2}$

$\mathrm{H}_{\mathrm{a}}$ : Biaya produksi usahatani buah naga skala sempit lebih tinggi dibandingkan dengan skala luas, atau $\mu_{1}>\mu_{2}$

3. Pengujian hipotesis yang ketiga mengenai keuntungan usahatani buah naga skala sempit lebih rendah dibandingkan dengan skala luas, menggunakan metode uji beda uji-Z. Uji yang digunakan analog dengan hipotesis yang pertama. Sementara itu, Untuk mengukur tingkat keuntungan usahatani buah naga menggunakan pendekatan analisis keuntungan dengan formulasi sebagai berikut (Sukirno,2001):

$$
\begin{aligned}
& \pi=T R-T C \\
& T R=P \cdot Q \\
& T C=T F C+T V C
\end{aligned}
$$

di mana:

$$
\begin{aligned}
& \pi=\text { Keuntungan }(\mathrm{Rp}) \\
& \text { TR }=\text { Total Penerimaan }(\text { Total Revenue) } \\
& \text { TC }=\text { Total Biaya (Total Cost }) \\
& \text { P }=\text { Harga Per Satuan Produksi (Price) }
\end{aligned}
$$

$\mathrm{Q}=$ Jumlah Produksi (kg) (Quantity)

$\mathrm{TFC}=$ Total Biaya Tetap (Total Fixed

Cost)

TVC = Total Biaya Variabel (Total

Variabel Cost)

\section{HASIL DAN PEMBAHASAN}

\section{Profil Petani Buah Naga}

Menurut Witrianto (2011), pembangunan agribisnis berawal dari kualitas petani sebagai pelaku utama. Kualitas petani berhubungan dengan profil petani yaitu luas lahan garapan, umur petani, pendidikan formal, dan pengalaman. Rata-rata luas lahan petani buah naga adalah $2.529 \mathrm{~m}^{2}$ dengan nilai minimum luas $2.500 \mathrm{~m}^{2}$ dan maksimum seluas $10.000 \mathrm{~m}^{2}$. Berdasarkan golongan petani menunjukka bahwa rata-rata luas lahan petani sempit sebesar $2.529 \mathrm{~m}^{2}$, sedangkan rata-rata luas lahan petani luas sebesar $9.300 \mathrm{~m}^{2}$. Pada nilai minimum petani golongan sempit sebesar $2.500 \mathrm{~m}^{2}$ dan nilai maksimum sebesar

\begin{tabular}{|c|c|c|c|c|c|}
\hline \multirow{2}{*}{ No } & \multirow{2}{*}{ Uraian } & \multirow{2}{*}{ Satuan } & \multicolumn{2}{|c|}{ Skala Petani } & \multirow{2}{*}{ Rata-rata Total } \\
\hline & & & Sempit & Luas & \\
\hline 1 & Luas Lahan & $\mathrm{m}^{2}$ & 2.529 & 9.300 & 4.068 \\
\hline 2 & Umur & Th & 51 & 49 & 50 \\
\hline 3 & Pendidikan & Th & 9 & 14 & 10 \\
\hline 4 & Pengalaman & Th & 2 & 4 & 3 \\
\hline
\end{tabular}
$3.000 \mathrm{~m}^{2}$. Petani golongan luas dengan nilai minimum sebesar $7.500 \mathrm{~m}^{2}$ dengan nilai maksimum sebesar $10.000 \mathrm{~m}^{2}$. Profil petani buah naga di Kecamatan Tegalsari, Kabupaten Banyuwangi disajikan pada Tabel 2.

Tabel 2. Profil Petani Buah Naga di Kecamatan Tegalsari, Kabupaten Banyuwang Tahun 2016

Sumber: Analisis data primer (2016).

Umur sangat mempengaruhi kemampuan yang dimiliki oleh setiap petani antara lain kemampuan fisik dan kemampuan berfikir. Rata-rata umur petani buah naga di Kecamatan Tegalsari Kabupaten Banyuwangi adalah 50 tahun. Selain faktor umur faktor pendidikan juga sangat berpegaruh penting khususnya dalam cara pemikiran petani terhadap usahatani buah naga. Berdasarkan pendidikan formal yang pernah ditempuh menunjukkan bahwa rata-rata total tingkat pendidikan petani sebesar 10 tahun atau setingkat SMA. Dalam usahatani buah naga pengalaman juga sangat berpengaruh dalam mengelola usahatani buah naga, berdasarkan pengalaman bertani dalam usahatani buah naga menunjukkan bahwa rata-rata total pengalaman bertani selama 3 tahun.

\section{Perbedaan Produktivitas Antar Skala Usaha}

Produktivitas adalah rasio dari total output dengan luas lahan yang dipergunakan dalam proses produksi. Produktivitas buah naga di Kecamatan Tegalsari, Kabupaten Banyuwangi disajikan pada Tabel 3. 
Tabel 3. Rata-rata Produktivitas per Hektar Usahatani Buah Naga di Kecamatan Tegalsari, Kabupaten Banyuwangi Tahun 2016

\begin{tabular}{cccc}
\hline \multirow{2}{*}{ Uraian } & \multicolumn{2}{c}{ Skala Usaha } & Rata-rata Total \\
\hline Produktivitas Lahan (kg/ha) & Sempit & Luas & 7.575 \\
\cline { 2 - 4 } & 7.190 & 8.883 &
\end{tabular}

Sumber: Data Primer, diolah tahun (2016).

Tabel 3 menunjukkan bahwa ratarata total produktivitas usahatani buah naga pada musim tanam 2016 di Kecamatan Tegalsari, Kabupaten Banyuwangi sebesar $7.575 \mathrm{~kg} / \mathrm{ha}$. Berdasarkan skala usaha ada perbedaan Produktivitas buah naga antar skala sempit dan skala luas. Produktivitas buah naga yang dihasilkan oleh golongan petani sempit sebesar $7.190 \mathrm{~kg} / \mathrm{ha}$, lebih sedikit dibanding skala luas sebesar $8.883 \mathrm{~kg} / \mathrm{ha}$ dengan selisih $1.693 \mathrm{~kg} / \mathrm{ha}$. Selisih tersebut nyata secara statistik pada taraf uji $10 \%$ berdasar uji beda-z satu arah sebagaimana dapat dilihat pada Tabel 4. Berdasarkan uji-z satu arah pada Tabel 4 bahwa produktivitas usahatani buah naga skala luas secara statistik nyata lebih tinggi dibanding skala sempit. Hal ini menunjukkan bahwa tidak selalu pengawasan pada skala luas menjadi lebih lemah.

Tabel 4. Uji beda-Z Satu Arah Produktivitas Buah Naga di Kecamatan Tegalsari, Kabupaten Banyuwangi

\begin{tabular}{cccccc}
\hline No & Petani & Mean & Z-hitung & Z-tabel & $\begin{array}{c}\text { Probabilitas } \\
\text { Signifikansi }\end{array}$ \\
\hline 1 & Skala Kecil & $7.190,20$ & $-1,39$ & 1,28 & $0,08^{*}$ \\
2 & Skala Luas & $8.883,33$ & & \\
\hline
\end{tabular}

Keterangan: Pengujian hipotesis menggunakan uji-z satu arah, di mana $*, * * * * *$ menyatakan signifikan masing-masing pada taraf kepercayaan $90 \%, 95 \%, 99 \%$.

Sumber: Analisis data primer (2016).

Perbedaan Biaya Produksi Buah Naga Berdasarkan Skala Usaha

Jenis biaya produksi yang dikeluarkan dalam usahtani buah naga dapat dibedakan menjadi dua macam yaitu biaya tetap dan biaya variabel. Berikut ini disajikan rincian struktur biaya pada usahatani buah naga di Kecamatan Tegalsari, Kabupaten Banyuwangi tahun 2016.

Tabel 5. Struktur Biaya per Hektar Usahatani Buah Naga di Kecamatan Tegalsari, Kabupaten Banyuwangi Tahun 2016

\begin{tabular}{|c|c|c|c|c|c|c|}
\hline \multicolumn{2}{|r|}{ Jenis Biaya } & \multicolumn{2}{|l|}{ Skala Sempit } & \multicolumn{2}{|l|}{ Skala Luas } & Rata-rata Total \\
\hline 1) & Sewa Lahan & 5.000 .000 & 20,01 & 5.000 .000 & 23,78 & 5.000 .000 \\
\hline & b. Penyangga & 835.686 & 3,35 & 540.917 & 2,57 & 768.693 \\
\hline & c. Pupuk Organik & 265.804 & 1,06 & 163.861 & 0,78 & 242.635 \\
\hline & d. Pengolahan Lahan & 119.137 & 0,48 & 118.789 & 0,57 & 119.058 \\
\hline & Jumlah & 6.689 .013 & 26,78 & 6.286.608 & 29,90 & 6.597 .557 \\
\hline \multicolumn{7}{|c|}{ Biaya Variabel } \\
\hline & Biaya Saprodi & 1.955 .529 & $\mathbf{7 , 8 3}$ & 1.335 .233 & 6,35 & 1.814 .553 \\
\hline & a. Pupuk & 1.570 .471 & 6,29 & 1.161 .233 & 5,52 & 1.477 .462 \\
\hline & b. Pestisida & 385.059 & 1,54 & 174.000 & 0,83 & 337.091 \\
\hline \multirow[t]{3}{*}{ 2) } & Biaya Tenaga Kerja & 16.337 .647 & 65 & 13.401 .000 & 64 & 15.670.227 \\
\hline & Jumlah & 18.293 .176 & 73,22 & 14.736 .233 & $\mathbf{7 0 , 1 0}$ & $\mathbf{1 7 . 4 8 4 . 7 8 0}$ \\
\hline & Total Biaya & 24.982 .190 & 100,00 & 21.022 .842 & 100,00 & 24.082.338 \\
\hline
\end{tabular}

Sumber: Analisis data primer (2016). 
Biaya produksi buah naga berdasarkan skala usaha menunjukkan adanya perbedaan yang dikeluarkan oleh masingmasing petani sempit dan petani skala luas. Bahwa golongan petani skala sempit mengeluarkan biaya produksi usahatani buah naga lebih tinggi dari pada biaya produksi usahatani buah naga yang dikeluarkan oleh golongan petani skala luas yaitu sebesar Rp. 24.982.190/ha sedangkan skala luas sebesar Rp. 21.022.842/ha.

Tabel 6. Uji beda-Z Satu Arah Biaya Produksi Buah Naga di Kecamatan Tegalsari, Kabupaten Banyuwangi

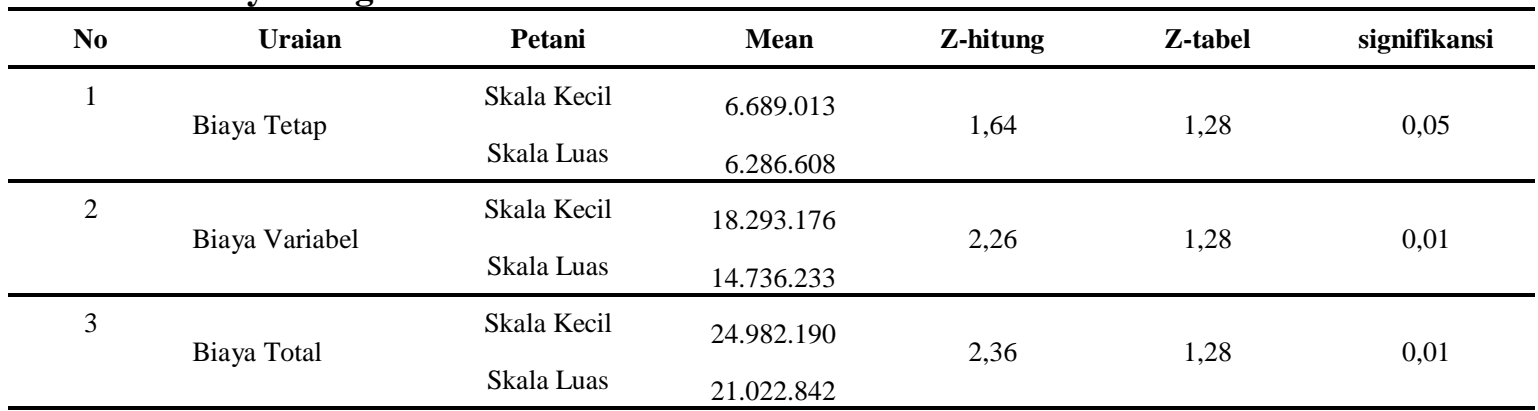

Keterangan: Pengujian hipotesis menggunakan Uji-Z satu arah, dimana $*, * *, * * *$ menyatakan siginifikansi masing-masing pada taraf kepercayaan $90 \%, 95 \%, 99 \%$.

Sumber: Analisis data primer (2016).

Berdasarkan uji-z satu arah pada Tabel 6 , terlihat bahwa biaya produksi buah naga secara nyata pada taraf uji $5 \%$ yang meliputi biaya tetap dan biaya variabel skala sempit lebih tinggi di banding skala luas. Hasil ini kemungkinan di sebabkan oleh berlebihan dalam penggunaan input pupuk, dan tenaga kerja, sehingga biaya menjadi tinggi.

\section{Perbedaan Keuntungan Usahatani Buah Naga Berdasarkan Skala Usaha}

Keuntungan adalah selisih antara penerimaan total dan biaya-biaya. Biaya ini dapat diklasifikasikan menjadi dua, yaitu biaya tetap dan biaya variabel. Untuk mengetahui rata-rata keuntungan usahatani buah naga di Kecamatan Tegalsari, Kabupaten Banyuwangi dapat dilihat pada tabel 7.

Tabel 7. Produksi, Biaya dan Keuntungan per Hektar Usahatani Buah Naga di Kecamatan Tegalsari, Kabupaten Banyuwangi Tahun 2016

\begin{tabular}{|c|c|c|c|c|c|}
\hline No & Uraian & \multicolumn{2}{|c|}{ Skala Petani } & $\begin{array}{l}\text { Rata-rata } \\
\text { Total }\end{array}$ & $\begin{array}{c}\text { Selisih Rata-rata } \\
\text { Total }\end{array}$ \\
\hline 1 & Produksi (kg) & 7.190 & 8.883 & 7.575 & -1.693 \\
\hline 2 & Harga (Rp) & 8.000 & 8.000 & 8.000 & 0 \\
\hline 3 & Penerimaan (Rp) & 57.521 .569 & 71.066 .667 & 60.600 .000 & -13.545 .098 \\
\hline 5 & Keuntungan (Rp) & 32.539 .379 & 50.043 .825 & 36.517 .662 & -17.504 .446 \\
\hline
\end{tabular}

Sumber: Analisis Data Primer (2016).

Tabel 7 menunjukkan bahwa rata-rata total sebesar $8.037 \mathrm{~kg} / \mathrm{ha}$. Sedangkan rata-rata total penerimaan sebesar Rp. 60.600.000/ha. Rata-rata total penggunaan biaya sebesar Rp. 24.082.338/ha. Sementara untuk keuntungan rata-rata total sebesar Rp. 36.517.662/ha. Selanjutnya berdasarkan uji-z satu arah pada Tabel 8, terlihat bahwa secara nyata pada taraf uji 5\% keuntungan skala sempit lebih rendah dibanding dengan skala luas.
Tabel 8. Uji beda-Z Dua Arah Keuntungan Buah Naga di Kecamatan Tegalsari, Banyuwangi

\begin{tabular}{|c|c|c|c|c|c|}
\hline $\begin{array}{l}\mathbf{N} \\
\mathbf{0}\end{array}$ & Petani & Mean & $\begin{array}{c}\text { Z- } \\
\text { hitung }\end{array}$ & $\begin{array}{c}Z- \\
\text { tabel }\end{array}$ & $\begin{array}{c}\text { Probabil } \\
\text { itas } \\
\text { Signifika } \\
\text { nsi }\end{array}$ \\
\hline 2 & $\begin{array}{l}\text { Skala } \\
\text { Kecil } \\
\text { Skala } \\
\text { Luas }\end{array}$ & $\begin{array}{c}32.539 \\
379 \\
50.043 \\
825\end{array}$ & $-1,95$ & 1,28 & $0,03^{*}$ \\
\hline
\end{tabular}


Keterangan: Pengujian hipotesis menggunakan Uji-Z satu arah, dimana $*, * *, * * *$ menyatakan siginifikansi masingmasing pada taraf kepercayaan $90 \%$, $95 \%, 99 \%$.

Sumber: Analisis data primer (2016).

\section{KESIMPULAN}

Berdasarkan hasil penelitian serta pembahasan, maka dapat disimpulkan bahwa; (1) Produktivitas usahatani buah naga untuk petani skala sempit lebih rendah dibandingkan dengan skala luas. Produktivitas buah naga untuk golongan petani skala sempit sebesar $7.190 \mathrm{~kg} / \mathrm{ha}$, sedangkan untuk skala luas sebesar $8.883 \mathrm{~kg} / \mathrm{ha}$. Perbedaan ini secara statistik signifikan pada taraf uji 1\%; (2) Biaya produksi usahatani buah naga untuk petani skala sempit lebih besar dibandingkan dengan skala luas. Biaya produksi untuk golongan petani skala sempit sebesar Rp. 24.982.190/ha dan skala luas sebesar Rp. 21.022.842/ha. Perbedaan ini secara signifikan pada taraf uji $5 \%$; (3) Keuntungan usahatani buah naga untuk petani skala sempit lebih rendah dibandingkan dengan skala luas. Keuntungan usahatani buah naga golongan petani sempit sebesar Rp. 32.539.379/ha dan skala luas sebesar Rp. 50.043.825/ha. Perbedaan ini secara signifikan pada taraf uji $5 \%$.

\section{DAFTAR PUSTAKA}

Adiyanto, J. 2011. Strategi Pengembangan Produksi Buah Naga Merah di Kabupaten Sukoharjo. Skripsi (dipublikasikan). Fakultas Pertanian, Universitas Sebelas Maret. Surakarta.

Boediono. 1982. Ekonomi Mikro. BPFE. Yogyakarta.

Departemen Pertanian. 2015. Peluang Budidaya Buah Naga. Badan Penelitian dan Pengembangan Pertanian, Departemen Pertanian. Jakarta.

Singarimbun, M. 1981. Metode Penelitian Survey. PT Pustaka LP3ES. Jakarta.

Soekartawi. 1995. Analisis Usahatani. UIPress. Jakarta.
Sukirno, S. 2001. Pengantar Teori Mikro Ekonomi. Edisi Kedua. Rajawali Press. Jakarta.

Supranto, J. 2009. Statistik Teori dan Aplikasi. Edisi ketujuh Jilid 2. Erlangga. Jakarta.

Sutiarso, E. 2015. Pedoman Teknik Penulisan Proposal Penelitian. Fakultas Pertanian, Universitas Muhammadiyah Jember. Jember.

Witrianto. 2011. Ada Apa dan Siapa Petani. Blogdetik.com. Jakarta. 